\title{
TUGAS ROH KUDUS DALAM MISI BERDASARKAN KITAB KISAH PARA RASUL
}

\author{
Randy Frank Rouw \\ Mahasiswa Pascasarjana Sekolah Tinggi Filsafat Jaffray Makassar \\ randyrouw@gmail.com
}

\begin{abstract}
This article was made with the aim of describing the duties of the Holy Spirit seen from the Book of Acts and their relation to the missionary mission. In researching this topic, the author uses a literature review of books. The results of the research related to the role of the Holy Spirit are: First, the Holy Spirit fulfills the students in the ministry. He also enabled them to witness to the name of Christ and give courage to them. Second, the Holy Spirit chooses certain people for His task. Third, the Holy Spirit leads His messengers in missionary service. Fourth, the Holy Spirit works in the church. Fifth, the Holy Spirit strengthens the disciples to witness through His faithful, steadfast and willing servants for Christ. Sixth, the Holy Spirit also fulfills Gentiles, which is evidence of equality between Jews and Gentiles.
\end{abstract}

Key words: acts, mission, holy spirit, duty

\begin{abstract}
Abstrak
Artikel ini dibuat dengan tujuan memaparkan tugas-tugas Roh Kudus dilihat dari Kitab Kisah Para Rasul dan kaitannya dalam misi pekabaran Injil. Dalam meneliti topik ini, penulis menggunakan tinjauan kepustakaan dari buku-buku. Hasil dari penelitian kaitannya dengan peran Roh Kudus adalah: Pertama, Roh Kudus memenuhi murid-murid dalam pelayanan. Ia juga memampukan mereka untuk bersaksi bagi nama Kristus dan memberikan keberanian kepada mereka. Kedua, Roh Kudus memilih orang-orang tertentu untuk tugasNya. Ketiga, Roh Kudus memimpin para utusan-Nya dalam pelayanan misi. Keempat, Roh Kudus berkarya dalam jemaat. Kelima, Roh Kudus menguatkan murid-murid untuk bersaksi melalui pelayan-Nya yang setia, teguh dan rela berkorban bagi Kristus. Keenam, Roh Kudus juga memenuhi orang-orang non-Yahudi yang mana ini menjadi bukti adanya kesetaraan antara orang-orang Yahudi dan non-Yahudi.
\end{abstract}

Kata-kata Kunci: Kisah Para Rasul, Misi, Roh Kudus, Tugas

\section{Pendahuluan}

Kekristenan dikenal dengan salah satu Doktrin yang cukup krusial dan kompleks, yaitu Ketritunggalan Allah. Allah yang esa, yang adalah satu, termanifestasi ke dalam tiga pribadi/oknum: Allah Bapa, Allah Anak - yaitu Yesus Kristus - dan Allah Roh Kudus. Harus diakui bahwa ini adalah kebenaran dan di luar dari pemahaman manusia. Masingmasing adalah pribadi dan ilahi, demikian juga dalam hal ini Roh Kudus. 
Keilahian Roh Kudus dinyatakan melalui beberapa bagian.Daniel Ronda memberikan beberapa kategori yang mana menjadi bukti akan keilahian Roh Kudus. ${ }^{1}$ Keilahian Roh Kudus terbukti dari sifat ilahi dan kesempurnaan-Nya. Ia kekal (Ibr. 9:14), Maha mengetahui (Yoh. 14:26, 16:12-13; 1 Kor. 2:10), Mahakuasa (Luk. 1:35), dan Mahahadir (Mazmur 139:7-10). ${ }^{2}$ Keilahian Roh Kudus juga terbukti melalui karya-karya-Nya. Ia terlibat dalam penciptaan (Ayb. 33:4), Roh Kudus yang memberi kehidupan (Kej. 2:7), serta Ia bernubuat (2 Sam. 23:2). ${ }^{3}$ Kemudian, keilahian Roh Kudus terbukti ketika nama-Nya disejajarkan juga dengan nama Allah dan Kristus. Dalam Matius 28:19, yang disebut sebagai Amanat Agung, nama Bapa, Anak dan Roh Kudus seolah-olah sejajar. Kemudian juga gambaran yang lebih jelas lagi adalah dalam kisah Ananias dan Safira; dusta yang mereka lakukan, Petrus dengan lugas mengatakan merupakan dusta terhadap Roh Kudus yang juga dusta terhadap Allah (Kis. 5:3-4). ${ }^{4}$ Keilahian dari Roh Kudus tidak dapat dipungkiri. Alkitab dengan jelas menyatakan bahwa Roh Kudus punya kualitas-kualitas keilahian.

Dalam kaitannya dengan pembahasan Roh Kudus, Boice mencatatkan bahwa seorang pribadi "memiliki pengetahuan, perasaan, dan kehendak" dan hal inijuga yang dinyatakan dalam Alkitab mengenai Roh Kudus. ${ }^{5}$ Yesus berkata dalam Yohanes 14:16-18: "Aku akan meminta kepada Bapa, dan Ia akan memberikan kepadamu seorang Penolong yang lain, supaya Ia menyertai kamu selama-lamanya, yaitu Roh Kebenaran. Dunia tidak dapat menerima Dia, sebab dunia tidak melihat Dia dan tidak mengenal Dia. Tetapi kamu mengenal Dia, sebab Ia menyertai kamu dan akan diam di dalam kamu." Roh Kudus disebutkan sebagai "Seorang Penolong," ia menyertai layaknya seorang pribadi, tidak hanya sebuah kuasa. Yesus menjanjikan seorang Penolong kepada murid-murid-Nya yang akan menggantikan-Nya setelah Ia pergi. Jelas bahwa Roh Kudus bukan hanya sekadar kuasa. Sang Penolong tersebut adalah,

... pribadi ilahi yang lain, satu Pribadi yang memiliki pengetahuan, karena Ia mengetahui kebutuhan-kebutuhan murid-murid itu; perasaan-perasaan, karena Ia menempatkan diri bersama mereka dalam kesediahan mereka; dan kehendak, karena Ia berketetapan untuk menghibur mereka dalam penggenapan akan penugasan Tuhan. ${ }^{6}$

Roh Kudus jelaslebih dari sebuah pemberian saja. Ia adalah ilahi, namun Ia juga memiliki kriteria layaknya seorang pribadi; yang berpengetahuan, berperasaan serta memiliki kehendak.

Tidak hanya melihat identitas, peran dari Roh Kudus juga besar dan tidak dapat diabaikan. Dalam Roma 8:2, Roh Kudus memberi hidup dan memerdekakan orang percaya dalam Kristus. Ia tinggal dan aktif di dalam orang percaya (ay. 9-11). Dalam jurnalnya, Chrismastianto mengutip Palmer yang mengatakan bahwa "Roh Kudus adalah pribadi yang menyatakan dan menginsyafkan kita terhadap dosa serta memimpin kita dengan kuasaNya, sehingga kita mengalami perjumpaan dengan Allah secara pribadi."7Rod Kudus

${ }^{1}$ Daniel Ronda, Dasar Teologi Yang Teguh: Panduan Teologi Sistematika di Perguruan Tinggi (Makassar: Sekolah Tinggi Theologia Jaffray, 2013), 96-98.

${ }^{2}$ Ronda, Dasar Teologi Yang Teguh, 96-97.

3Ibid., 97.

${ }^{4}$ Ibid., 97-98.

5James Montgomery Boice, Dasar-Dasar Iman Kristen (Surabaya: Momentum, 2011), 426.

'Ibid., 427.

${ }^{7}$ E. H. Palmer, The Holy Spirit His Persons and Ministry (New Jersey: P\&R Publishing Company, 2005); Imanuel Adhitya Wulanata Chrismastanto, "Peran dan Karya Roh Kudus serta 
menginsyafkan dosa dan memimpin orang percaya untuk berjumpa dengan Allah. Bahkan kaitannya dengan seni, Roh Kudus juga terlibat. Jeremy S. Begbie menuliskan bahwa modern ini dipahami bahwa Roh Kudus juga terlibat dalam penginspirasian suatu karya musik atau puisi; ada kaitan antara seni dengan kuasa ilahi. ${ }^{8}$ Peran dan karya Roh Kudus masih banyak dan dapat dijabarkan lebih lagi. Namun, semua bertujuan pada satu hal.

Karya utama Roh Kudus adalah memuliakan Yesus. Sependapat dengan Boice, dalam bukunya tercatat bahwa "Sesungguhnya, ketika dipahami secara tepat, semua karya lain yang dapat disebutkan adalah termasuk di dalam satu tujuan yang utama ini." 9 Memuliakan dan meninggikan Kristus Yesus menjadi peran utama Roh Kudus. Semua tindakan-Nya sebenarnya berfokus untuk mencapai tujuan ini, yaitu memuliakan Anak Allah. Demikian hal dengan misi.

Salah satu peran Roh Kudus adalah dalam bidang misi. Roh Kudus punya peran besar dalam pelayanan misi orang-orang percaya. Boice menuliskan bahwa Roh Kudus yang membuka "mata-mata yang buta" sehingga pada akhirnya mereka dapat melihat kepentingan akan Kristus, Sang Juruselamat.10Tanpa Roh Kudus, orang-orang tidak dapat dengan sungguh-sungguh dibawa untuk melihat kepentingan mereka untuk menerima Yesus Kristus. Selain itu, Roh Kudus juga berkarya melalui murid-murid Yesus waktu itu dan terlihat jelas di dalam Kisah Para Rasul. Dalam A Biblical Theology of the New Testament, ditegaskan bahwa memang Roh Kudus berkarya dalam misi. Roh Kudus yang memulai kegerakan sehingga terciptanya sebuah persekutuan gereja mula-mula. "Permulaan zaman baru dalam karya Allah telah datang." 11 Namun, saya peran Roh Kudus saat ini dilupakan.

Francis Chan menulis buku yang berjudul Forgotten God, yang merujuk kepada Roh Kudus. Dalam pengamatannya, Francis Chan menilai bahwa Roh Kudus telah diabaikan dan juga dilupakan. Ia menilai, dalam misi, keberadaan Roh Kudus pun diabaikan. ${ }^{12}$ Jimmy H. Evans III juga memandang demikian. Evans menilai bahwa zaman ini adanya kekurangan pengetahuan terhadap Roh Kudus, karya-Nya dan peran-Nya. Bahkan yang sangat disayangkan adalah adanya ketidakpercayaan terhadap pribadi Roh Kudus; lebih banyak orang tidak paham akan pribadi yang disebut Penolong ini. Hal ini mengakibatkan iman yang lemah, mencegah akan adanya kuasa, dan relasi dengan Tuhan yang kaku/sulit.13 Seperti yang Evans katakan, hal ini berbahaya bagi iman Kristen. Iman lemah, tidak ada kuasa dan hubugan yang kaku dengan Allah, mengikuti orang-orang yang tidak percaya atau mengabaikan Roh Kudus.

Hal ini mendorong penulis untuk membahas akan tugas/peran Roh kudus di dalam pelayanan misi secara khusus dalam Kitab Kisah Rasul. Seperti yang penulis sudah tuliskan,

Implikasinya terhadap Pengembangan Pribadi dan Kualitas Pengajaran Guru Kristen," A Journal of Language, Literature Culture, and Education: POLYGLOT14, no. 1 (Januari 2018):22, diakses 30 Maret 2019, https://ojs.uph.edu/index.php/PII/article/view/326/pdf.

'Jeremy S. Begbie, "The Holy Spirit at Work in the Arts: Learning From George Herbert," Interpretation: A Journal of Bible and Theology66, no. 1 (2012):41, diakses 30 Maret 2019, https://doi.org/10.1177/0020964311425310.

${ }^{9}$ Boice, Dasar-Dasar Iman Kristen, 432.

${ }^{10}$ Ibid., 435-36.

${ }^{11}$ Roy B. Zuck, ed., A Biblical Theology of the New Testament (Malang: Gandum Mas, 2011), 107.

${ }^{12}$ Francis Chan, Forgotten God: Reversing Our Tragic Neglect of the Holy Spirit (U.S.A.: David C. Cook, 2009), 15, diakses 30 Maret 2019,https://books.google.co.id/books?id=Byk0L51q80UC\&printsec=frontcover\&dq=forgotten + God\&hl=en\&s $\underline{\mathrm{a}=\mathrm{X} \& \mathrm{ved}=0 \text { ahUKEwis7eikxuLhAhUZk3AKHU8vAFUQ6AEILTAA\#v=onepage \&q\&f=false. }}$.

13Jimmie Evans, "The Third Person of the Trinity: How the Holy Spirit Facilitates Man's Walk with God," Fidei et Veritatis: The Liberty University Journal of Graduate Research 1, no. 1 (20 Januari 2016):1, diakses 30 Maret 2019, https:/ / digitalcommons.liberty.edu/fidei_et_veritatis/vol1/iss1/8. 
Roh Kudus berperan penting dalam pelayanan misi, secara khusus yang dilakukan oleh murid-murid dalam Kisah Rasul. Dalam narasi kitab ini, terlihat bahwa dibalik pelayanan dan kehidupan para murid-murid Kristus, ada kuasa dan pimpinan Roh Kudus.

\section{Tugas Roh Kudus Dalam Misi ${ }^{14}$ Roh Kudus Memenuhi Murid-murid ${ }^{15}$}

Dalam buku A Biblical Theology of the New Testament tertulis bahwa pemenuhan Roh Kudus dalam tulisan Lukas menjelaskan tentang kehadiran serta pemberian kuasa atau kemampuan.16 Berkaitan dengan pemenuhan Roh Kudus dalam misi, penulis membagi menjadi 2 bagian, yaitu Roh Kudus memberikan kuasa kepada murid-murid serta memberikan kemampuan untuk bersaksi.

Pertama, Roh Kudus memberikan kuasa kepada murid-murid dalam misi. Ini yang dijanjikan di dalam Kisah Para Rasul 1:8, bahwa murid-murid akanmenerima kuasa jikalau Roh Kudus turun ke atas mereka dan mereka sekalian akan menjadi saksi di Yerusalem, seluruh Yudea dan Samaria sampai ujung bumi. Roh Kudus memberikan kuasa dengan berbagai bentuk. Mukjizat dan tanda-tanda tidaklah dapat dikesampingkan sebagai karya Roh Kudus.

Banyak kali dicatatkan bahwa murid-murid mengadakan mukjizat serta tanda. Pasal 2 mencatatkan bahwa rasul-rasul mengadakan tanda-tanda dan mukjizat (ay. 43) dan ini mungkin jika ada kuasa dari Roh Kudus, seperti yang diungkapkan Andrew Brake dalam bukunya, "Adapun, tanda dan mukjizat yang diadakan para rasul dalam jemaat yang mulamula mengalir langsung dari Roh Kudus yang bersemayam dalam diri mereka serta dalam persekutuan gereja mereka." 17 Selain itu masih banyak mukjizat dan tanda lain yang rasulrasul lakukan dalam pelayanan mereka (3:6-7; 5:1-11, 12; 9:34-35, 40-41; 14:8-10). Inilah wujud nyata penyertaan Roh Kudus dalam misi yang dijalankan rasul-rasul; Ia memberikan kuasa untuk mengadakan mukjizat dan tanda. Pada akhirnya orang-orang takut dan gentar serta memuliakan Tuhan.

Kemudian, Roh Kudus menyatakan kuasa saat Petrus dan Paulus menegur. Dalam pelayanan misi, teguran beberapa tokoh terhadap orang lain menjadi suatu hal yang juga memberikan dampak besar bagi orang-orang yang menyaksikan, seperti dalam peristiwa yang dialami oleh Petrus dan Paulus. Dalam pasal 5, Petrus menegur Ananias dan Safira karena tindakan mereka yang Petrus anggap sebagai dusta terhadap Roh Kudus (ay. 3 dan 9) atau terhadap Allah sendiri (ay. 4). Respons orang-orang menjadi takut melihat kejadian tersebut (ay. 11). Bock menuliskan bahwa respons takut adalah kesadaran bahwa Allah hadir saat itu dan dapat bertindak menghukum atau menghakimi.18 Peristiwa ini sangat berpengaruh kepada orang-orang percaya yang melihat. Petrus dengan keberanian dan kuasa dari Roh Kudus menegur Ananias dan Safira; dan Allah - secara tidak langsung menunjukkan kehadiran-Nya. Melalui peristiwa itu, orang-orang percaya menyaksikan bahwa Allah serius terhadap dosa mereka (Ananias dan Safira); orang-orang dibawa untuk melihat Allah dan kuasa-Nya. Berkaitan dengan misi, orang-orang yang telah percaya tetap dipelihara untuk hidup seturut kehendak Tuhan.

14 Sebagian besar poin di dalam artikel ini diinspirasi dari buku Roy B. Zuck, ed., A Biblical Theology of the New Testament (Malang: Gandum Mas, 2011), 107-109.

15 Penulis artikel memisahkan pemenuhan Roh Kudus atas murid-murid dengan pemenuhan Roh Kudus atas orang-orang dari bangsa lain karena akan dibahas dalam poin yang lain.

16Zuck, ed., A Biblical Theology of the New Testament, 108.

${ }^{17}$ Andrew Brake, Menjalankan Misi Bersama Yesus (Bandung: Kalam Hidup, 2016), 51.

${ }^{18}$ Darrell L. Bock, Baker Exegetical Commentary on the New Testament: Acts (Grand Rapids, Michigan: Baker Academic, 2007), 227. 
Selain Petrus, Paulus juga harus menegur dalam pimpinan Roh dan tanpa sadar tegurannya memberikan dampak kepada seorang gubernur di Pulau Pafos. Dalam pasal 13:9-11 Paulus memberi teguran keras seorang tukang sihir dan nabi palsu (ay. 6) yang bernama Baryesus atau Elimas. Karena berusaha membelokkan iman gubernur (ay. 8,10), dengan penuh Roh Kudus Paulus menegurnya dan menyatakan hukuman Tuhan atas Elimas (ay. 9-11). Melihat mukjizat yang terjadi (Elimas benar-benar buta), gubernur itupun percaya dan takjub dengan ajaran Tuhan (ay. 12). ${ }^{19}$ Dalam pelayanan misi, seorang gubernur menjadi percaya dan takjub dengan ajaran Tuhan melalui peristiwa di mana kuasa Tuhan nyata ketika Paulus dengan penuh Roh Kudus menegur seorang penyihir.

Kedua, Roh Kudus memenuhi murid-murid dan memampukan mereka untuk bersaksi. Roh Kudus bekerja dan memampukan murid-murid memberitakan mengenai Yesus Kristus. Dalam Kisah Para Rasul 2:1-12, Roh Kudus memberikan kuasa sehingga rasul-rasul sehingga mereka dapat berbicara dalam bahasa-bahasa lain. Ada lidah-lidah api yang hinggap pada mereka dan Roh Kudus memenuhi mereka. Roh Kudus memimpin mereka berbicara, bersaksi kepada orang banyak. Brake menyatakan hal ini adalah kuasa dari Roh Kudus dan menjadi bagian penting dalam misi Roh Kudus yaitu menjangkau bangsa-bangsa. ${ }^{20}$

Kuasa pemberitaan Injil Yesus Kristus jelas terlihat juga dalam kisah Petrus, Stefanus dan Paulus. Mereka memberitakan tentang Yesus Kristus dengan jelas dan berani. Mereka menjelaskan mengenai pemberontakan orang-orang, perlawanan terhadap Yesus yang adalah Mesias yang dinantikan. Mereka menegur orang karena pemberontakan mereka. Namun mereka juga memberikan pengharapan dalam pemberitaan kabar baik. Meskipun tidak sedikit orang menolak, namun banyak orang yang datang dan bertobat melalui pemberitaan tokoh-tokoh tersebut. Mereka menyerahkan diri mereka dan bertobat. Yesus diberitakan dan orang-orang diselamatkan. Itu karya Roh Kudus; memampukan rasul-rasul untuk bersaksi tentang Yesus Kristus.

Kemampuan yang Roh Kudus beri kepada rasul-rasul dan orang-orang percaya juga dibarengi dengan keberanian dalam bersaksi. Dalam pasal 2, Roh Kudus hadir dan memberikan kuasa kepada murid-murid dalam peristiwa turunnya lidah-lidah api di atas para murid. Dalam situasi ini, mereka dimampukan untuk berbicara dalam bahasa-bahasa lain. Roh Kudus memberikan keberanian kepada mereka untuk bersaksi kepada orang banyak saat itu. Ia juga memberikan keberanian kepada Petrus untuk berkhotbah di depan orang banyak. Petrus menegur banyak orang karena mereka sudah membunuh Yesus Kristus. Dengan lancar dan terus terang, Petrus menyampaikan berita yang keras. Itulah karya Roh Kudus. Melalui khotbah Petrus, orang-orang tertegur dan menyerahkan diri untuk bertobat serta dibaptis $(2: 14-36,41)$.

Dalam Kisah Para Rasul 4:8, dikisahkan juga Petrus dengan beraninya - ketika ia dipenuhi Roh Kudus - membela dirinya di depan para pemimpin dan tua-tua, karena ia memberitakan tentang nama Yesus. Kisah Rasul 4:31 juga menggambarkan bagaimana Roh Kudus bekerja memberikan keberanian kepada para murid untuk bersaksi dan memberitakan firman Allah. Karya Roh Kudus dalam memberikan keberanian tidak berhenti sampai di situ. Dalam peristiwa yang dialami Stefanus pun Ia bekerja.

Di hadapan para orang Farisi, Stefanus bertanya jawab dengan mereka tanpa takut. Yang menarik adalah itu merupakan dorongan dari Roh Kudus (6:10). Keberaniannya dalam pembicaraannya dengan orang-orang adalah karena Roh Kudus. Roh Kudus yang

19 Meskipun itu tidak jelas, kemungkinan gubernur itu percaya kepada Yesus Kristus atau percaya kepada kuasa ilahi yang baru saja ia lihat. David J. Williams, Understanding The Bible Commentary Series: Acts (Grand Rapids, Michigan: Baker Books, 2011), 226.

${ }^{20}$ Brake, Menjalankan Misi Bersama Yesus, 28-29. 
memberikan dorongan kepada Stefanus untuk berbicara dan bersaksi. Bahkan diakhir hidupnya, sebelum ia dirajam, ia masih memiliki keberanian untuk berbicara dan bersaksi bahwa ia melihat Yesus Kristus (7:55).

Paulus juga memperoleh keberanian dari Roh Kudus. Ketika ia pertama kalinya bertobat dan bertemu Ananias, Ananias berkata bahwa Paulus akan dipenuhi oleh Roh Kudus. Benarlah demikian yang dialami Paulus. Roh Kudus memenuhi dirinya dan itu dibuktikan dengan keberaniannya untuk bersaksi kepada orang banyak tentang Yesus yang sebelumnya ia tentang $(9: 17,20-22)$. Banyak orang yang takut dan bertanya-tanya mengenai Paulus, karena sebelumnya ia adalah pembunuh orang-orang yang mengikut Kristus, Namun, Roh Kudus-lah yang memberanikan dirinya untuk tetap bersaksi meskipun diperhadapkan dengan situasi ketidakpercayaan dan kebingungan orang-orang.

Paulus juga menunjukkan keberaniannya, ketika ia menegur dengan keras Elimas dan itu karena Roh Kudus (13:9-12). Roh Kudus juga menganugerahkan keberanian kepada Paulus ketika ia hendak pergi ke Yerusalem. Banyak orang yang menasihati agar tidak pergi karena akan ada bahaya (21:4,12). Bahkan Agabus juga menunjukkan hal apa yang akan dialami Paulus ketika di sana (21:11). Namun, dengan keberanian Paulus berkata siap pergi ke sana, bahkan mati di sana demi memberitakan Injil (21:13). Memang ini merupakan tekad yang kuat dari Paulus, namun tidak lain juga itu adalah keberanian dan kekuatan yang Roh Kudus anugerahkan dalam memberitakan Injil.

Inilah peran Roh Kudus dalam memenuhi murid-murid: ia memberikan kuasa dan memampukan mereka dalam memberitakan Injil. Pertama, Roh Kudus nyata memberikan kuasa ketika rasul-rasul mengadakan banyak mukjizat dan tanda, kemudian ketika Petrus dan Paulus menegur. Kedua, Roh Kudus memampukan murid-murid untuk bersaksi dan kemampuan itu disertai dengan keberanian.

\section{Roh Kudus Memilih21}

Tugas kedua adalah Roh Kudus memilih. Roh Kudus punya kuasa untuk memilih orang-orang tertentu untuk kepentingan pelayanan misi. Dalam narasi Kisah Para Rasul 13:2 terlihat jelas Roh Kudus punya peran langsung dalam memutuskan Paulus dan Barnabas untuk pelayanan misi. Ketika jemaat di Antiokhia sedang berdoa dan berpuasa, berkatalah Roh Kudus kepada, "Khususkanlah Barnabas dan Saulus bagi-Ku untuk tugas yang telah Kutentukan bagi mereka." Meskipun kemungkinan Roh Kudus tidak tiba-tiba berbicara langsung dan bisa didengar oleh semua orang ketika sedang bersekutu, ${ }^{22}$ namun dari narasi ini kita dapat melihat peran langsung dari Roh Kudus dalam memilih hamba-hamba-Nya untuk misi. Pilihan-Nya juga tidaklah sembarangan. Seperti yang diungkapkan Andrew Brake, Roh Kudus memilih orang-orang yang berkualitas, bukan orang-orang "sisa" atau yang tidak siap pergi bersama-Nya. ${ }^{23}$

Dalam pelayanan pemeliharaan jemaat, Roh Kudus juga berperan memilih orangorang tertentu untuk memimpin jemaat. Ketika Paulus berada di Miletus, Paulus hendak bertemu dengan para penatua jemaat di Efesus (20:17). Selain karena alasan tidak akan bertemu lagi dengan mereka, pertemuan Paulus dengan para penatua merupakan kesempatan Paulus untuk menguatkan para pemimpin-pemimpin tersebut. Paulus memberikan nasihat untuk menjaga diri dan kawanan. Dengan tegas Paulus menyatakan mereka adalah orang-orang "yang ditetapkan Roh Kudus" (20:28). Bock mencatatkan: "The

21 Poin ini terinspirasi dari Diktat Kisah Para Rasul karya Andrew Brake, Ceramah 1.

22 Sepertinya jemaat sedang bergumul dalam pelayanan misi dan mencari seseorang untuk pergi bermisi. Roh Kudus sepertinya tidak secara langsung berbicara, namun Ia berfirman melalui seorang nabi dan nabi tersebut menyampaikan kepada orang-orang dalam persekutuan tersebut. David J. Williams, Understanding The Bible Commentary Series: Acts, 222.

${ }^{23}$ Brake, Menjalankan Misi Bersama Yesus. 
role as overseer came from appointment by the Spirit, either by prophetic naming and/or recognition by the church." 24 Peran sebagai gembala atau penatua merupakan pemilihan dari Roh Kudus sendiri. Roh Kudus berkuasa untuk menetapkan orang-orang untuk kepentingan Allah, dalam hal ini memimpin dan menggembalakan jemaat-Nya.

Sebagai yang tertera di atas, tugas Roh Kudus yang kedua adalah memilih orangorang tertentu untuk kepentingan misi Allah. Ia memilih Barnabas dan Paulus untuk pelayanan misi dan Ia juga memilih para penatua untuk pelayanan penggembalaan jemaat Allah yang adalah buah pelayanan misi.

\section{Roh Kudus Memimpin Utusan Allah Dalam Pelayanan Misi}

Tugas ketiga adalah Roh Kudus memimpin utusan-Nya dalam pelayanan misi. Tidak sedikit dikisahkan Roh Kudus secara langsung mengarahkan apa yang harus dilakukan oleh hamba-hamba-Nya. Hal ini dialami oleh Filipus. Roh Kudus memimpin ia langsung dalam pelayanan. Roh Kudus mengarahkan Filipus untuk mendekati sebuah kereta dalam perjalanannya menuju ke Yerusalem (8:29). Akhirnya ia bertemu dengan seorang sida-sida dari Etiopia yang sedang kesulitan untuk mengerti sebuah nas dalam Perjanjian Lama, tepatnya Yesaya 53:7-8 (8:30-34). Filipus pun berkesempatan menjelaskan nas tersebut dan memberitakan tentang Injil Yesus (8:35). Melalui arahan langsung dari Roh Kudus, Filipus dapat peluang memberitakan Injil kepada seorang penting dari Etiopia. Akhirnya pun, orang tersebut berinisiatif untuk meminta dibaptis dan Filipus membaptisnya (8:36-38).

Masih dalam kisah yang sama, setelah membaptis sida-sida Etiopia dan setelah mereka berdua keluar dari air, tiba-tiba Roh Tuhan "melarikan" Filipus ke Asdod (8:39-40). Kata yang dipakai untuk "melarikan" adalah harpazo (caught up) ${ }^{25}$ dapat berarti menangkap, mengambil, membawa. Dalam hal ini Filipus dengan "paksa" ditangkap atau dibawa langsung oleh Roh Tuhan atau Roh Kudus ke Asdod. Bock menyatakan bahwa pemidahan Filipus ke Asdod menyatakan/memperjelas bahwa Tuhan masih bekerja ${ }^{26}$ dan memang ini merupakan pekerjaan Tuhan. Melalui Roh-Nya, Tuhan memimpin Filipus untuk melanjutkan pelayanan misi. Setelah tiba di Asdod, Filipus melanjutkan tugasnya untuk memberitakan Injil, bahkan sampai tiba di Kaisarea.

Petrus juga mengalami pimpinan Roh Kudus ketika ia berada di atas sebuah rumah. Roh Kudus memberitahukan kepadanya bahwa ada 3 orang yang mencarinya. Roh menyuruhnya untuk turun dan menemui mereka (10:19-20). Mereka adalah utusan dari Kornelius. Pesan yang penting dari Roh Kudus menurut Bock adalah agar Petrus tidak "mendiskriminasi" /" membedakan" sikapnya terhadap orang-orang tersebut. ${ }^{27}$ Roh Kudus mau supaya Petrus pergi bersama-sama dengan mereka dan jangan menjadi bimbang (10:20). Petrus mengikuti pimpinan dari Roh Kudus dan peristiwa ini menjadi jalan awal di mana pandangan Petrus dan banyak orang-orang Yahudi mengenai orang-orang dari bangsa lain diubahkan. Kebenarannya adalah Allah juga menerima, menyelamatkan dan mengaruniakan Roh-Nya kepada orang-orang dari bangsa lain yang percaya.

Selain Filipus dan Petrus, Paulus juga mengalami pimpinan Tuhan. Ketika ia berencana untuk pergi melayani di Asia bersama Silas, Roh Kudus mencegah mereka (16:6). Tidak jelas mengapa Roh Kudus mencegah mereka. Menurut Bock, kemungkinan karena saat itu Asia bukanlah target pelayanan misi Allah. ${ }^{28}$ Roh Kudus memimpin Paulus dan Silas

${ }^{24}$ Bock, Baker Exegetical Commentary on the New Testament: Acts, 630.

25 Dipakai 2 kali di dalam Kisah Para Rasul. Bock, Baker Exegetical Commentary on the New Testament: Acts,345-46.

26Ibid., 346.

27Ibid., 391.

${ }^{28}$ Bock mengutip pendapat Moule (An Idiom-Book of New Testament Greek, 1959, 100). Ibid., 526. 
untuk melayani di Makedonia. Dalam pimpinan-Nya, Injil pun tersebar di Makedonia dan banyak orang dikuatkan melalui pelayanan Paulus dan Silas. Itu semua karena Roh Kudus memimpin hamba-hamba-Nya dalam pelayanan misi. Demikianlah tugas Roh Kudus yang ketiga; Ia memimpin utusan-utusan-Nya dalam pelayanan misi.

\section{Roh Kudus Berkarya Dalam Jemaat}

Tugas berikutnya dari Roh Kudus adalah berkarya dalam jemaat. Dalam Kisah Rasul 9:31, disebutkan bahwa jemaat mengalami pertumbuhan jumlah oleh karena Roh Kudus. Melalui pertolongan dan penghiburan-Nya, jemaat mengalami pertumbuhan. Roh Kudus berkarya di dalam jemaat sehingga terjadi pertumbuhan. Selain itu, kembali ke pasal 4 (ay. 31), setelah jemaat berdoa bersama, Roh Kudus memenuhi jemaat dan memberikan keberanian kepada mereka untuk memberitakan firman Allah dengan berani. Melalui peristiwa ini, pastinya Injil semakin tersebar. Karya Roh Kudus tidak berhenti sampai di situ saja.

Diinformasikan dalam Kisah Para Rasul 2 dan 4, jemaat yang saat itu percaya hidup bersama dan tidak ada yang kekurangan. Mereka rela menjual harta bendanya dan membagi-bagikan kepada jemaat yang lain, sehingga tidak ada yang kekurangan (2:44-45; 4:32-35). Kehidupan jemaat yang saling berbagi dan penuh kerelaan untuk menjual harta juga bagian dari karya Roh Kudus di dalam jemaat. Jemaat yang percaya oleh karena pelayanan misi, terus dipelihara di dalam Roh Kudus. Kehidupan mereka yang rela menjual harta dan saling berbagi menunjukkan bahwa Roh Kudus bekerja di dalam jemaat. Selain itu dalam pasal 2, jemaat mula-mula hidup bertekun di dalam pengajaran dan doa, mereka juga menjual harta dan berbagi serta saling memecahkan roti (ay. 42,46). Semua merupakan hasil dari karya Roh Kudus di dalam jemaat. Dalam buku A Biblical Theology of the New Testament terdapat penyataan yang mendukung bahwa Allah melalui Roh Kudus yang bekerja di dalam gereja dan membentuk jemaat-Nya.

Dalam Gereja yang sedang berkembang, Allah melalui Roh Kudus bekerja membentuk suatu kelompok baru terdiri orang-orang yang setia dan menjadi teladan. Itu juga bagian dari rencana-Nya. Allah yang merancang dan peduli telah memanggil umatNya kepada kehidupan kemuridan dan pelayanan, suatu kehidupan yang berbeda dengan cara hidup dunia yang egois. ${ }^{29}$

Pemberitaan akan Yesus telah diterima dan orang-orang menjadi percaya. Allah tidak berhenti bekerja. Melalui Roh Kudus, Ia terus memelihara dan berkarya di dalam jemaat sehingga jemaat terus bertumbuh.

\section{Roh Kudus Menguatkan Murid-murid Melalui Pelayan-Nya}

Selain berkarya dalam jemaat, Roh Kudus juga bertugas menguatkan setiap murid secara khusus agar mereka siap dan berani dalam bersaksi. Salah satu cara yang menurut penulis juga dipakai Roh Kudus untuk menguatkan murid-murid untuk memberitakan Injil adalah Ia memakai pelayan-Nya. Ia memakai pelayan Allah untuk menjadi saksi bagi para murid. Tidak terlalu jelas, namun ini dapat dilihat dalam peristiwa ketika Paulus hendak pergi ke Yerusalem.

Sesampainya di Tirus, Paulus mengunjungi murid-murid di situ. Oleh karena Roh Kudus, murid-murid memperingatkan Paulus agar tidak pergi ke Yerusalem (21:3-4).

${ }^{29}$ Zuck, A Biblical Theology of the New Testament, 109. 
Sepertinya Roh Kudus menyatakan kepada para murid apa yang akan dihadapi oleh Paulus, ${ }^{30}$ oleh sebab itu mereka memperingatkan Paulus. Namun, respons mereka berbeda antara murid-murid dengan Paulus. Williams menyatakan bahwa Paulus melihat peringatan ini untuk mempersiapkan diri menghadapi tantangan di depan, namun murid-murid melihat itu sebagai tanda untuk mundur dalam pelayanan. ${ }^{31}$ Peringatan ini tidak hanya datang dari murid-murid. Seorang nabi bernama Agabus datang dan bahkan memperagakan apa yang akan dialami oleh Paulus di Yerusalem (21:10-11). Namun, hal itu tetap tidak menggoyahkan Paulus; Ia dengan tegas tetap akan pergi ke Yerusalem. ${ }^{32}$ Ia bahkan menyatakan diri rela mati karena nama Tuhan Yesus. Paulus menunjukkan kesiapan, keberanian serta tekadnya untuk pergi demi Kristus; jikalau ia harus mati, ia pun siap. Hal ini yang menurut penulis memengaruhi para murid yang melihat dan mendengar Paulus.

Tekad serta semangat rela berkorban yang dimiliki Paulus untuk pergi bersaksi bagi Yesus dipakai oleh Roh Kudus untuk menguatkan murid. Itulah mengapa Ia (seperti dengan sengaja) "membisikkan" atau menyatakan penderitaan yang akan dialami Paulus kepada murid-murid. Roh Kudus hendak menguatkan murid-murid. Ia mau supaya murid-murid saat itu melihat Paulus; keteguhan hatinya, keberaniannya, serta kerelaannya untuk mati demi Kristus. Itu yang akan menguatkan mereka, memotivasi mereka nantinya untuk memiliki semangat bersaksi yang sama, seperti Paulus. Demikianlah tugas dari Roh Kudus; Ia menguatkan jemaat untuk bersaksi dengan cara memakai hamba-Nya yang teguh dan rela berkorban untuk Kristus.

\section{Roh Kudus Memenuhi Orang-orang Non-Yahudi}

Tugas Roh Kudus juga tidak hanya memenuhi murid-murid atau orang-orang Yahudi saja, namun ada bukti bahwa Roh Kudus juga memenuhi orang-orang non Yahudi. Dalam Kisah Para Rasul 8:14-17, Roh Kudus memenuhi orang-orang Samaria. Di dalam bagian yang lain, yaitu Kisah Para Rasul 10:44-48, dicatatkan bahwa Roh Kudus juga turun kepada bangsa-bangsa non-Yahudi. Hal ini menjadi bukti bahwa Allah menerima dan hendak menyelamatkan bangsa-bangsa lain yang percaya juga (28:28). Dalam buku A Biblical Theology of the New Testament tertacat demikian,

Pencurahan Roh Allah atas komunitas ini tidak hanya menunjukkan datangnya "harihari terakhir" (2:17), tetapi juga menunjukkan (pada saat Dia dicurahkan kembali dalam Kisah Para Rasul 10) bahwa bangsa-bangsa lain dan bangsa Yahudi adalah setara dalam rencana Allah (11:15-18). Mereka menjadi bagian yang sama dalam komunitas baru itu..$^{33}$

Ada kesetaraan antara bangsa Yahudi dan bangsa-bangsa lain dalam rencana Allah. Hal ini dibuktikan dengan tinggalnya Roh Kudus dalam orang-orang non-Yahudi. Hal ini menjadi kesaksian besar, tidak hanya bagi orang-orang Yahudi, namun juga kepada orangorang dari bangsa lain.

30 Bock dan Williams memiliki pandangan yang sama; Roh Kudus menyatakan apa yang akan dihadapi oleh rasul Paulus dalam pelayanannya. Bock, Baker Exegetical Commentary on the New Testament: Acts, 636-637, Williams, Understanding The Bible Commentary Series: Acts, 360.

${ }^{31}$ David J. Williams, Understanding The Bible Commentary Series: Acts.

32 Brake mengungkapkan hal yang penting. Keputusan Paulus untuk tetap pergi bukanlah suatu bentuk ketidaktaatan pada tuntunan Roh Kudus. Justru, karena kendali Roh Kudus, dengan keteguhan hati ia siap untuk pergi ke Yerusalem. Brake, Menjalankan Misi Bersama Yesus.

${ }^{33}$ Zuck, A Biblical Theology of the New Testament, 107. 
Melalui karya Roh Kudus kepada bangsa-bangsa lain dalam pelayanan misi, akan menjadi kesaksian yang amatlah besar kepada orang-orang Yahudi yang percaya saat itu. Tuhan juga mengasihi dan menyelamatkan orang-orang dari bangsa lain. Ini menjadi kesaksian bagi umat Allah dari bangsa Yahudi. Ketika Petrus berbicara dengan Kornelius dan orang banyak, seketika Roh Kudus turun ke atas mereka dan mereka mulai berbicara dalam bahasa roh dan memuliakan Tuhan. Hal ini membuat semua orang percaya dari golongan bersunat yang saat itu bersama-sama dengan Petrus tercengang-cengang (10:4445). Menurut David J. Williams, hal ini mencengangkan karena orang-orang Yahudi sudah didiktum (atau menerima keputusan yang resmi) bahwa Roh Kudus tidak pernah turun atas orang-orang yang tidak bersunat atau atas orang-orang non-Yahudi ${ }^{34}$ dan dalam kasus ini, berbeda dari apa yang selama ini sudah mereka percayai. "God had unquestionably poured out the gift of the Holy Spirit on these Gentiles." 35 Allah tanpa dipertanyakan lagi mencurahkan Roh Kudus atas orang-orang non-Yahudi. Hal ini menjadi kesaksian yang mencengangkan bagi orang-orang percaya Yahudi. Petrus bersaksi kepada orang-orang bersunat di Yerusalem bahwa Roh Kudus juga turun atas orang-orang tidak bersunat; banyak orang yang akhirnya percaya dan menerima akan hal itu (11:1-18).

Selain itu, turunnya Roh Kudus juga menjadi kesaksian yang nyata bagi orang-orang dari bangsa lain itu sendiri. Mereka disadarkan bahwa mereka juga merupakan umat pilihan Allah. Brake menuliskan, "Allah juga berkenan kepada mereka. Ia senang menyatakan diriNya kepada mereka." 36 Allah juga hendak menyelamatkan bangsa-bangsa lain. Tanda yang dapat mereka lihat dan rasakan adalah dengan hadirnya Roh Kudus dalam diri mereka dan Ia menguasai diri mereka. Bukti Roh Kudus menguasai mereka adalah mereka dapat seketika itu juga berbicara dalam bahasa roh dan memuliakan Allah (10:46).

Seperti yang telah dipaparkan di atas, Roh Kudus juga berperan dalam memenuhi orang-orang golongan non-Yahudi. Ini tugas yang penting dalam pelayanan misi. Ini membuktikan bahwa Allah juga menganggap setara orang-orang dari bangsa lain dalam rencana keselamatan. Peristiwa Roh Kudus memenuhi orang-orang non-Yahudi juga menjadi kesaksian yang besar: baik bagi orang-orang Yahudi sendiri maupun bagi orangorang non-Yahudi.

\section{Kesimpulan}

Roh Kudus memiliki tugas yang tidak tergantikan dalam misi. Peran-Nya sangat penting dan tidak bisa diabaikan. Pertama, Roh Kudus memenuhi murid-murid dalam pelayanan. Ia memenuhi dan menganugerahkan rasul-rasul kuasa dalam pelayanan sehingga nama Tuhan semakin dikenal dan dimuliakan. Bahkan melalui teguran, Roh Kudus juga bekerja menyatakan kuasa-Nya. Ia juga memampukan mereka untuk bersaksi bagi nama Kristus dan memberikan keberanian kepada mereka. Kedua, Roh Kudus memilih orang-orang tertentu untuk tugas-Nya, baik dalam pelayanan misi ataupun dalam memelihara jemaat yang adalah buah dalam pelayanan misi. Roh Kudus memilih orangorang yang berkualitas. Ketiga, Roh Kudus memimpin para utusan-Nya dalam pelayanan misi. Hal ini yang membuat Injil semakin tersebar dan banyak orang dikuatkan; karena Roh Kudus memimpin para pelayan-Nya ke tujuan yang tepat. Keempat, Roh Kudus berkarya dalam jemaat. Ia menguatkan jemaat dalam persekutuan dan membuat jemaat bertumbuh. Kelima, Roh Kudus menguatkan murid-murid untuk bersaksi melalui pelayan-Nya yang setia, teguh dan rela berkorban bagi Kristus. Keenam, Roh Kudus juga memenuhi orang-

\footnotetext{
${ }^{34}$ David J. Williams, Understanding The Bible Commentary Series: Acts, 196.

35 Ibid.

36Brake, Menjalankan Misi Bersama Yesus, 249.
} 
orang non-Yahudi. Ini menjadi bukti adanya kesetaraan antara orang-orang Yahudi dan non-Yahudi. Karya-Nya menjadi kesaksian tidak hanya bagi orang-orang Yahudi sendiri, namun juga bagi orang-orang non-Yahudi.

\section{Rujukan}

Begbie,Jeremy S. "The Holy Spirit at Work in the Arts: Learning From George Herbert." Interpretation: A Journal of Bible and Theology 66, no. 1 (2012):41-54. Diakses 30 Maret 2019. https://doi.org/10.1177/0020964311425310.

Bock,Darrell L. Baker Exegetical Commentary on the New Testament: Acts. Grand Rapids, Michigan: Baker Academic, 2007.

Boice, James Montgomery. Dasar-Dasar Iman Kristen. Surabaya: Momentum, 2011.

Brake, Andrew. Menjalankan Misi Bersama Yesus. Bandung: Kalam Hidup, 2016.

Chan, Francis. Forgotten God: Reversing Our Tragic Neglect of the Holy Spirit. U.S.A.: David C. Cook, 2009. Diakses 30 Maret 2019.

https://books.google.co.id/books?id=Byk0L51q80UC\&printsec=frontcover\&dq=forgotten + Go $\mathrm{d} \& \mathrm{hl}=\mathrm{en} \& \mathrm{sa}=\mathrm{X} \& \mathrm{ved}=0 \mathrm{ahUKEwis7eikxuLhAhUZk3AKHU8vAFUQ6AEILTAA \# v= \text {onepage }}$ $\& \mathrm{q} \& \mathrm{f}=$ false.

Chrismastanto, Imanuel Adhitya Wulanata. "Peran dan Karya Roh Kudus serta Implikasinya terhadap Pengembangan Pribadi dan Kualitas Pengajaran Guru Kristen." A Journal of Language, Literature Culture, and Education: POLYGLOT 14, no. 1 (Januari 2018):19-30. Diakses 30 Maret 2019.

https://ojs.uph.edu/index.php/PJI/article/view/326/pdf.

David, J. Williams. Understanding The Bible Commentary Series: Acts. Grand Rapids, Michigan: Baker Books, 2011.

Evans, Jimmie. "The Third Person of the Trinity: How the Holy Spirit Facilitates Man's Walk with God." Fidei et Veritatis: The Liberty University Journal of Graduate Research 1, no. 1 (20 Januari 2016): 1-12. Diakses 30 Maret 2019. https://digitalcommons.liberty.edu/fidei_et_veritatis/vol1/iss1/8.

Ronda, Daniel. Dasar Teologi Yang Teguh: Panduan Teologi Sistematika di Perguruan Tinggi. Makassar: Sekolah Tinggi Theologia Jaffray, 2013.

Zuck, Roy B. ed. A Biblical Theology of the New Testament. Malang: Gandum Mas, 2011. 